\title{
Corrigendum: Long-Term Outcomes of Successful Revascularization for Patients With Coronary Chronic Total Occlusions: A Report of 1,655 Patients
}

OPEN ACCESS

Approved by:

Frontiers Editorial Office,

Frontiers Media SA, Switzerland

*Correspondence:

Lei Guo

leiguo@dmu.edu.cn

Specialty section: This article was submitted to Atherosclerosis and Vascular

Medicine

a section of the journa Frontiers in Cardiovascular Medicine

Received: 28 January 2021 Accepted: 29 January 2021 Published: 15 February 2021

Citation:

Guo L, Zhang $X, L v H$, Zhong L, Wu J,

Ding $H, X u$ J, Zhou $X$ and Huang $R$

(2021) Corrigendum: Long-Term

Outcomes of Successful

Revascularization for Patients With

Coronary Chronic Total Occlusions: A Report of 1,655 Patients.

Front. Cardiovasc. Med. 8:659972.

doi: 10.3389/fcvm.2021.659972
Lei Guo ${ }^{1 *}$, Xiaoyan Zhang ${ }^{2}$, Haichen $L v^{1}$, Lei Zhong ${ }^{1}$, Jian $W u^{1}$, Huaiyu Ding ${ }^{1}$, Jiaying $X u^{1}$, Xuchen Zhou ${ }^{1}$ and Rongchong Huang ${ }^{1,3}$

${ }^{1}$ Department of Cardiology, The First Affiliated Hospital of Dalian Medical University, Dalian, China, ${ }^{2}$ Department of Radiology, Fuyang Hospital of Anhui Medical University, Fuyang, China, ${ }^{3}$ Department of Cardiology, Capital Medical University Affiliated Beijing Friendship Hospital, Beijing, China

Keywords: cardiac mortality, coronary chronic total occlusions, major adverse cardiac event, medical therapy, percutaneous coronary intervention, successful revascularization, outcomes

\section{A Corrigendum on}

Long-Term Outcomes of Successful Revascularization for Patients With Coronary Chronic Total Occlusions: A Report of 1,655 Patients

by Guo, L., Zhang, X., Lv, H., Zhong, L., Wu, J., Ding, H., et al. (2020). Front. Cardiovasc. Med. 7:116. doi: $10.3389 / f c v m .2020 .00116$

In the published article, there was an error in the author affiliations. Instead of "Rongchong Huang ${ }^{3}$," it should be "Rongchong Huang ${ }^{1,3}$."

The authors apologize for this error and state that this does not change the scientific conclusions of the article in any way. The original article has been updated.

Copyright $\odot 2021$ Guo, Zhang, Lv, Zhong, Wu, Ding, Xu, Zhou and Huang. This is an open-access article distributed under the terms of the Creative Commons Attribution License (CC BY). The use, distribution or reproduction in other forums is permitted, provided the original author(s) and the copyright owner(s) are credited and that the original publication in this journal is cited, in accordance with accepted academic practice. No use, distribution or reproduction is permitted which does not comply with these terms. 